\title{
Reflexões epistemológicas no ensino de ciências/química: as potencialidades da pedagogia científica de Bachelard
}

\section{Sthefen Fernando Andrade Da Ronch \\ sthefen@upf.br \\ $43-8635$ \\ Universidade de Passo Fundo, Passo Fundo, Rio Grande do Sul, Brasil \\ Ocsana Sonia Danyluk ocsana@upf.br \\ 0000-0002-2146-0562 \\ Universidade de Passo Fundo, Passo Fundo, Rio Grande do Sul, Brasil \\ Alana Neto Zoch \\ alana@upf.br \\ Universidade de Passo Fundo, Passo \\ Fundo, Rio Grande do Sul, Brasil}

\begin{abstract}
RESUMO
Atualmente, as tecnologias têm facilitado o alcance de informações pelos alunos, contudo esse acesso à informação não remete a um acesso ao conhecimento, e acaba por gerar um desinteresse na Educação Escolar, vista tradicionalmente como meio de acesso a informação e ao conhecimento. A educação escolar tem então o desafio de se reinventar. Quando se fala do Ensino de Ciências/Química, a situação não é diferente, encontra-se um ensino desconexo e longe de algo que possa apresentar sentido de cultura científica para os alunos. A pedagogia científica de Bachelard, e suas discussões sobre o novo espírito científico, apresentam-se como uma prática de problematização sobre os objetos de estudo escolares. O novo espírito científico torna-se então um contributo para uma reorientação epistemológica na busca por um Ensino de Ciências com significado, sentido de cultura científica para os alunos com um viés de formação para a vida.
\end{abstract}

PALAVRAS-CHAVE: Pedagogia científica. Epistemologia. Ensino de ciências. 


\section{INTRODUÇÃO}

Vive-se hoje uma era na qual as informações estão facilmente ao alcance de todos, na distância de um toque com respostas quase instantâneas, sem exigir maiores pensamentos e reflexões. Essa situação também gera reflexos na escola, incluindo o Ensino de Química, baseando-o em conceitos e informações superficiais, tende-se a fazer dela a ciência da memória, do empírico. A Química, então, torna-se, muitas vezes, massa disforme de informações destituídas de lógica (LOPES, 2007). Por meio da transmissão de "verdades" ou conceitos/situações não problematizadas, os alunos encontram também o conteúdo quase que de forma instantânea, estanque, desconexa, sem reflexão e sem questionamento relacionado ao que está sendo discutido.

As práticas docentes, são geralmente marcadamente positivistas, muitas vezes vazias de perguntas e questionamentos, baseando-se apenas em verdades, quando a ciência não reproduz uma verdade, seja ela verdade dos fatos ou das faculdades do conhecimento. Ainda, tendem a desconsiderar a bagagem dos alunos, não fazendo a problematização dos conceitos, em uma busca por verificar e compreender as concepções prévias dos estudantes, o que colabora no assentamento dos obstáculos epistemológicos, ao tratar o aluno como uma tábula rasa. Essa abordagem da ciência conduz a percepção de uma ciência empírica e indutiva, que não estabelece relações entre os conceitos, e que faz ciência a partir da retificação de conceitos (LOPES, 2007).

O conhecimento científico, então é abordado de uma maneira que induz o aluno a percebê-lo como absoluto e distante de sua realidade, de sua vivência, desvinculando a educação em ciências de seu sentido, como prática social e histórica, e, principalmente, de um processo contínuo de refutação (FONSECA, 2008), que é a base do conhecimento científico. Weber (2005) descreve o fazer ciência como um conjunto de reflexões e ligações ao invés da utilização de conhecimentos tácitos e acabados.

\footnotetext{
O facto de a ciência ser, hoje, uma "profissão" que se realiza através da especialização em prol da tomada de consciência de si mesmo e do conhecimento de determinadas conexões reais, e não um dom gratuito, fonte de bênçãos e de revelações, na mão de visionários e de profetas, nem também uma parte integrante da reflexão de sábios e de filósofos sobre o sentido do mundo - constitui um dado inelutável da nossa situação histórica, a que não podemos escapar, se quisermos ser fiéis a nós próprios. (p. 29)
}

\section{BACHELARD E A FILOSOFIA DA DESILUSÃO}

Gaston Bachelard (1884-1962) foi um filósofo e professor de ciências francês, que dedicou boa parte de sua obra a reflexões sobre a ciência e sua compreensão, originando o que posteriormente seria chamado de epistemologia bachelardiana (LOBO, 2008). Os estudos de Bachelard, foram ao sentido de discutir uma nova visão de ciência, tendo em vista, os avanços e descobertas científicas feitas por seus contemporâneos, tornava-se necessário discutir uma nova visão de ciências, o que ele chamou de novo espírito científico.

Bachelard foi pioneiro ao tentar imprimir na atividade científica, uma discussões sobre essa necessidade de reflexão no ensino de ciências (LOBO, 2008). 
Um dos principais objetivos de Bachelard era fazer um contraponto ao cartesianismo e o positivismo, fortemente estabelecidos na atividade científica e no ensino de ciências.

Como pensais?, quais são as vossas tentativas?, os vossos ensaios, os vossos erros?, Quais são as motivações que vos levam a mudar de opinião? Por que razão vocês se exprimem tão sucintamente quando falam das condições psicológicas de uma nova investigação? Transmitam-nos sobretudo as vossas ideias fixas, as vossas convicções não confirmadas [...] Digam-nos o que pensam, não ao sair do laboratório, mas sim nas horas em que deixais a vida comum para entrar na vida científica. (BACHELARD APUD LOBO, p. 91, 2008).

A obra de Bachelard demonstra a importância não somente do fazer ciência, mas, sobretudo, as reflexões que devem ser feitas a partir da ciência, e ainda, pedagogicamente falando, no caso do ensino de ciências, principalmente em Química e Física, onde ele fez suas principais contribuições. Japiassú, em sua obra "Para ler Bachelard" (1976), discute a pertinência da obra de Bachelard, como fundamentalmente importante para o ensino, onde baseando-se nas reflexões de Bachelard, conclui que elas traduzem-se em uma pedagogia científica. Japiassú justifica sua posição a partir de quatro observações que faz em relação à obra de Bachelard:

a. Ao dizer que o conhecimento científico é sempre "a reforma de uma ilusão", Bachelard não somente sintetiza sua concepção de conhecimento como processo contínuo de retificação [...]

b. Bachelard não admite a existência de uma ciência superficial [...]

c. O racionalismo bachelardiano é aberto. Porque na verdade, nada permanece estável: os conceitos científicos devem ser retificados e deformados, os fundamentos da ciência têm necessidade de serem sempre reassegurados

[...]d. O próprio Bachelard caracteriza sua posição como sendo um "idealismo militante" [...] Donde a necessidade de uma nova Razão, de uma razão que não conheça apenas aquilo que ela conseguiu aprender, mas que, para pensar, deva tentar desaprender muito daquilo que aprendeu. [...] Em suma, "é necessário devolver à razão humana sua função turbulenta e agressiva". (JAPIASSÚ, 1976, p. 71-72)

Uma análise da obra de Bachelard nos revela um filósofo das ciências, que luta contra todo falso saber. Nos mostra um homem apaixonado por uma ciência da solidariedade inter-conceitual (JAPIASSÚ, 1976), e simultaneamente por uma experiência que provoca e remodela as ideias, sendo essas segundo ele bases do novo espírito científico.

\section{REFLEXÕES EPISTEMOLÓGICAS SOBRE O ENSINO DE CIÊNCIAS/QUÍMICA}

À Educação em Ciências subjaz um fundo reflexivo (LOPES, 1993), e a transformação da prática docente implica em mudança de concepção do próprio trabalho pedagógico, muitas vezes conservador, centrado em relações autoritárias na reprodução e manutenção do conhecimento acrítico e deslocado da realidade 
Também não é o objetivo, uma simplificação da ciência e de seus caracteres para tentar uma aproximação com os alunos, mas sim, instigar nos alunos, provocá-los à dúvida, ao questionamento, para que não aceitem o repasse automático de conteúdos vazios de problematização e de significado.

Segundo Fonseca (2008), o conhecimento se estrutura da fronteira do desconhecido e do conhecido, provocando uma constante necessidade de rupturas, e a possibilidade de olhares múltiplos sobre um mesmo objeto. E nesse contexto, hábitos e posturas - marcadamente positivistas - encharcam o trabalho docente, dificultando assim a aprendizagem em ciências, caracterizando os chamados obstáculos epistemológicos de Bachelard. Em "A formação do espírito científico", logo no início do primeiro capítulo, Bachelard declara sua convicção de que é em termos de obstáculos que se deve colocar o problema do conhecimento científico, em seguida discute a noção de obstáculo epistemológico.

O conceito de obstáculo epistemológico torna-se relevante na ação docente do ensino de ciências, daí a necessidade de que os professores tenham consciência dos obstáculos que se impregnam em sua prática docente. Se esquecem de que os adolescentes já chegam às aulas com algum conhecimento empírico já adquirido (JAPIASSÚ, 1976). O trabalho docente não consiste em levá-los a adquirir uma cultura científica, mas sim, que eles mudem de cultura científica, superando os obstáculos que já haviam criado a partir da sua vida cotidiana.

\footnotetext{
Logo, toda cultura científica deve começar [...], por uma catarse intelectual e afetiva. Resta, então, a tarefa mais difícil: colocar a cultura científica em estado de mobilização permanente, substituir o saber fechado e estático por um conhecimento aberto e dinâmico, dialetizar todas as variáveis experimentais, oferecer enfim à razão razões para evoluir. (BACHELARD, 2005, p. 24)
}

O trabalho educativo no ensino de ciências baseia-se essencialmente em uma relação dialógica com o que se observa/percebe do objeto de estudo) e o sujeito cognoscente (aluno), onde não há apenas a troca de ideias, percepções, mas sim, uma construção de percepções, que deve ser mediada pelo professor, como cita Lopes (1993) ao afirmar que não existem respostas prontas ou perguntas previsíveis, mas, a constante aplicação do pensamento para a elaboração de um hipertexto.

A aula deve ser planejada e conduzida, de modo que existam momentos onde o estudante possa estruturar seu conhecimento através do exercício do pensamento, refletindo, observando, indagando, enriquecendo sua autonomia intelectual e desenvolvendo seu pensamento crítico. Cabe ao professor, fazer perguntas não com o objetivo de dar ou receber as respostas prontas, mas sim, de construí-las em conjunto com os estudantes, percebendo a multiplicidade de respostas que se pode obter a partir da interpretação do seu objeto de estudo.

Na realidade não há fenômenos simples; o fenômeno é um tecido de relações. Não há natureza simples, nem substância simples, por que a substância é uma contextura de atributos. Não há ideias simples, por que uma ideia simples, como viu Dupréel, deve ser inserida, para ser compreendida num sistema complexo de pensamentos e experiências. (BACHELARD APUD FONSECA 2008, p. 363). professores de Química. 
Considero a questão epistemológica central na formação inicial e continuada dos professores, sendo uma das hipóteses de trabalho: a mudança pedagógica exige uma compreensão sólida da natureza da ciência que se deseja ensinar, pois os professores não abrem mão do que fazem enquanto acreditarem que a ciência química é um conjunto de verdades, descobertas por cientistas químicos, e que saber Química é memorizar e saber repetir essas verdades ou partes delas. (MALDANER, 2003, p. 96)

Maldaner (2003) discute então, a necessidade da compreensão dos professores da natureza do conhecimento científico, de modo que o percebam como um constante processo de construção e desconstrução de teorias e conceitos, e é essa mutabilidade que o caracteriza como tal.

A figura do professor desempenha importante papel neste processo. Ao conduzir a aprendizagem de um modo tácito, não demonstra aos alunos a significação de cada tema, e de como a Química pode interagir com o meio e thes proporcionar uma melhor qualidade de vida (MALDANER, 2003). Isso cria nos alunos imagens desfiguradas da ciência e do conteúdo que está sendo trabalhado.

Torna-se necessário, repensar práticas e ações nas quais o Ensino de Química possa ser problematizado, no sentido da construção de um espírito científico (BACHELARD, 1979), aproximando a educação escolar do racionalismo científico capaz de proporcionar aos estudantes um ensino com fundo reflexivo e crítico e com sentido de cidadania, como indicam Praia, Cachapuz e Gil-Pérez (2002):

A crítica, a argumentação e o consenso dos pares constituem elementos de racionalidade científica que importa desenvolver conjuntamente - alunos e professores - partilhando e vivendo dificuldades inerentes à própria prática científica. Desta maneira, tal exercício escolar permite uma aprendizagem efetiva, significativa e com sentido de cidadania. (2002, p.259)

Uma experiência interessante neste aspecto é o trabalho com oficinas temáticas, desenvolvido pelo Grupo de Pesquisa em Educação Química (GEPEQ), a qual reforça a ideia de levar em conta os elementos vivenciais do aluno como objetos de aprendizagem e ponto de partida para o desenvolvimento de conhecimentos que tenham um alcance mais amplo. Os autores ainda pontuam, que a utilização de um tema apenas para introduzir um conteúdo disciplinar específico não configura um objeto de estudo (SILVA, 2007, p.14), pois, nessa perspectiva não fornece subsídios para que o aprendiz compreenda aspectos relevantes sobre o assunto como os sociais, ambientais e tecnológicos.

Sangiogo e Zanon (2014) relatam que espaços de formação inicial onde se desenvolvem estudos em forma de pesquisa coletiva sobre situações vivenciadas no cotidiano extra-escolar, tomadas como objetos de estudo e aprendizagem na perspectiva de sua (re)significação conceitual, à luz das ciências, tem permitido avanços importantes na compreensão da química como ciência e de seu ensino.

Compreender a especificidade do papel do professor e da escola na (re)contextualização pedagógica dos conteúdos do ensino de química/ciências é uma condição essencial à formação de professores na perspectiva da produção de um conhecimento escolar mais significativo e socialmente relevante (2014, p.147).

Nesse sentido, as discussões realizadas entre professores, em espaços de formação inicial e continuada, bem como, na própria escola, contribuem para que as abordagens realizadas nas aulas, baseiem-se em uma constante 
problematização dos objetos de estudo escolares. Esse movimento, contribui para a constituição de uma educação em ciências, com fundo reflexivo e com sentido de cidadania, o que se apresenta como uma marca da pedagogia científica de Bachelard.

\section{AS POSSIBILIDADES DO NOVO ESPÍRITO CIENTÍFICO NO ENSINO DE CIÊNCIAS/QUÍMICA}

Segundo Bacherlard (1979), o novo espírito científico contrapõe-se ao cartesianismo. Ele percebe o conhecimento científico como algo em processo permanente de retificação e ainda potencializa esse conhecimento sob a perspectiva da educação e de sua aplicabilidade no Ensino de Ciências como uma prática social e histórica, dado que fazemos a educação em um referido contexto e com referidos objetivos. Nessa perspectiva, o sentido do Ensino de Ciências não são as respostas que este pode fornecer, mas sim, a perguntas que são possíveis que se façam a partir dele, ou seja, o sentido da dúvida, sendo essa a verdadeira marca do espírito científico.

A criticidade apresenta-se como uma marca de um ensino com essas características. Um ensino pautado por uma pedagogia essencialmente crítica (FONSECA, 2008) onde suas bases estão na problematização dos objetos de estudo com vistas à constituição de uma autonomia intelectual dos alunos, sua formação científica e desenvolvimento de possíveis vocações para as ciências. Como cita Fonseca:

\footnotetext{
Segue-se que tornar o científico mais pedagógico significa utilizar formas de pedagogia que situem os alunos como sujeitos críticos, que problematizem o conhecimento, que lancem novas questões, gerando novos desafios e novas questões-problema/soluções, "retificando" a ciência e os métodos científicos. (2008, p. 368).
}

Todo o conhecimento apresentado aos alunos é (no sentido de como foi constituído) e deve representar (no sentido de como deve ser apresentado aos estudantes) a resposta a uma dúvida, a uma inquietação no espírito que levou à problematização e à pesquisa; se não há problema/dúvida não haverá respostas. Essa pedagogia com cunho científico procura estimular o aluno na sua capacidade de inquietar-se (FONSECA, 2008), de estar em permanente questionamento com o conhecido, com o senso comum, e com os conceitos que lhe são apresentados pelo professor.

A pedagogia científica e o espírito científico buscam fortalecer os vínculos entre aluno e professor, principalmente por meio de uma perspectiva de pesquisa. Nesse sentido, o docente e o estudante se alinham, combinam, discutem, questionam, aproximam o conhecimento científico que antes era fixo e "dos livros" em algo que foi por eles construído, através das discussões e relações que fizeram para construir a sua interpretação sobre o conhecimento. Assim, pesquisa e ensino constituem-se como processos interligados e interativos, onde se possa criar uma abordagem em que o professor possa ocupar o lugar de aluno e o aluno o lugar de professor, sem haver uma hierarquização do ensino e da relação professor/aluno.

No trabalho com os conceitos, o professor pode priorizar uma abordagem fenomenológica de discussão, de interpretação sobre o objeto de estudo, não buscando habituar os alunos a terem respostas prontas, mas sim, conduzindo-os a 
uma cultura de questionamento, de reflexão, de dúvida. Bachelard apud Fonseca (2008) afirma que ao fugirmos da perspectiva de questionamento chega uma altura em que o espírito gosta mais daquilo que confirma o seu saber do que o contradiz; prefere as respostas às perguntas, sendo esse um grande desafio na aprendizagem em ciências.

As teorias e conceitos devem ser repensados de forma inter-relacionada, e sempre que possível demonstrando o seus impactos nas populações. No entanto, os alunos não devem perceber a ciência como sendo um prolongamento do senso comum, ou como algo que é necessário apenas para elucidação de observações do senso comum, caracterizando-a assim como uma ciência utilitarista, mas de uma forma que os conceitos sejam apresentados estabelecendo-se uma relação entre eles, de interdependência, demonstrando que os conhecimentos são produzidos a partir de relações com outros conhecimentos já existentes, e principalmente, como atendimento a uma dúvida. A ideia, não é criar uma nova cultura científica nos alunos, mas sim, mudar a que eles já possuem, caso contrário, teremos duas explicações para um fenômeno, uma científica e uma do senso comum, e para os alunos não há relação alguma entre elas.

Bachelard (1979) afirma que há um esgotamento da perspectiva positivista, contrária a proposta por ele e por Praia, Cachapuz e Gil-Pérez (2002) de constantes afirmação e certezas, indicando o nascimento de uma pedagogia científica. Para isso, é indispensável que haja uma transformação da prática docente como um todo, alterando assim a concepção atual de trabalho do professor, carregada de métodos acríticos e desconexos da realidade. Este tipo de abordagem fortalece o pensamento científico junto aos estudantes, pois eles percebem uma constante luta entre ideias e fatos que constituem o progresso do conhecimento (LOPES, 1993).

Fazem parte ainda deste conjunto de reflexões, que Bachelard (1971) classifica como Estatuto Epistemológico, a proposição de hipóteses e a experimentação. A proposição de hipóteses ocupa papel central na construção do conhecimento. Praia, Cachapuz e Gil-Pérez (2002) classificam a hipótese dentro de uma perspectiva racionalista como fundamental à construção do conhecimento científico, a qual por essência possui um fundo reflexivo. Isso porque a hipótese é levantada com base em uma prévia reflexão sobre os conhecimentos que já se tem sobre algo, considerando-a como uma paragem provisória do pensamento. As hipóteses tornam-se o ponto central do diálogo entre as teorias e concepções prévias e as observações, tudo isso mediado pelo professor.

Assim como as hipóteses, a experimentação faz parte do estatuto epistemológico proposto por Bachelard. Contudo o que se percebe é a realização de atividades experimentais conduzidas com pendor empirista, sem problematização ou questionamentos acerca do que está sendo observado e construído (GALLIAZI; GONÇALVES, 2004), percebe-se experimentação empirista do fazer para extrair a teoria, com uma abordagem tradicional do demonstrar para crer, contribuindo para manter a hegemonia de uma visão de Ciência objetiva, neutra, apoiada nas teorias surgidas da observação.

A experimentação poderia ser valorizada, sob esta perspectiva bachelardiana, como uma abordagem problematizadora e com questionamentos que venham a tomar lugar entre professor e estudante. Para se fazer ciência são necessários dados, os quais, em uma abordagem empirista, reduzem-se a uma manipulação de 
variáveis. Por outro lado, sob uma perspectiva investigativa, com cunho racionalista, previamente à realização da experimentação já são levantadas hipóteses, baseadas em parâmetros que foram observados pelos estudantes e/ou fornecidos pelo professor. A partir disso constroem-se hipóteses relacionadas ao fenômeno objeto de estudo (PRAIA, CACHAPUZ E GIL-PÉREZ, 2002).

Uma das grandes diferenças entre estes dois tipos de abordagem, é que sob uma perspectiva racionalista não importa a confirmação da teoria, mas sim que a construção significativa do conceito se dará quando o próprio estudante refutar a sua percepção anterior baseada em uma nova, que ele construiu durante a experimentação. Praia, Cachapuz e Gil-Pérez (2002) citam Popper quando expõem que a experimentação deve buscar a refutação das hipóteses e não a sua confirmação. Nesse contexto, mora uma grande oportunidade para o professor problematizar os prováveis erros ou percepções erradas contidas nas hipóteses levantadas pelos estudantes, assim, durante a realização da atividade experimental, o professor deve buscar questionar os estudantes acerca do que esta sendo observado e questioná-los a respeito do que observam. O erro e a irreflexão devem ser explorados, pois, não é a partir da repetição ponto por ponto dos conceitos que estão sendo estudados que os alunos conseguirão compreender o objeto de estudo, deve-se explorar a discussão entre os estudantes mediada pelo professor. Bachelard estava consciente de que o homem, quando só, está sempre em má companhia. A ciência, não mais a do cogito, porém a do cogitamos, cria uma sociedade estudiosa, onde os espíritos educam uns aos outros. (JAPIASSÚ, 1976).

Na discussão e mediação dos conceitos/conteúdos com os alunos, torna-se relevante que o docente faça a problematização dos objetos de estudo, promovendo discussões entre os estudantes, como exemplo, durante a realização de atividades de sistematização, criando o que Praia, CACHAPUZ E GIL-PÉREZ 2002) chamam de comunidade científica de alunos, proporcionando momentos em que haja a discussão entre eles e a resolução conjunta das atividades propostas, caracterizando uma perspectiva pedagógica de cunho científico.

O professor, ao mediar essa construção, deve buscar auxiliar os alunos a adquirir crenças nas suas próprias capacidades, de modo que eles venham a expor suas ideias, hipóteses e percepções acerca do objeto de estudo, mas tendo a clareza que não se deve perder o rigor intelectual, ou seja, tratar os seus conhecimentos de vivência (senso comum) como conhecimentos científicos, sem fazer uma reflexão.

\section{CONSIDERAÇÕES FINAIS}

Diante das dificuldades do trabalho docente e de como torná-lo mais significativo para os estudantes, às reflexões epistemológicas de Bachelard e sua pedagogia científica, apresentam-se como contributos para uma reorientação do trabalho docente nesse caminho de busca. Cabe ao docente, repensar a sala de aula como um espaço múltiplo formado por sujeitos inseridos em um contexto e já detentores de conhecimento empíricos do mundo material baseados em suas observações.

Tanto o professor quanto os alunos possuem histórias individuais, uma caminhada, valores, ideias, visões de mundo, e estão inseridos em uma 
comunidade com uma dada realidade. Nesse sentido, a escola como um todo, deve ser repensada.

As percepções, ideias, pensamentos e concepções sobre o ensino como um todo, ou propriamente sobre o ensino de Química, marcam a ação pedagógica, daí a importância de refletir sobre o que se pensa e se deseja ensinar.

Essa pedagogia científica pode encontrar terreno fértil na escola, através de práticas de planejamento em conjunto entre os professores das diversas áreas do conhecimento. Fazendo então, que a construção do conhecimento científico e o processo contínuo de refutação do conhecimento comum/conhecimento empírico seja feito sob uma perspectiva dialética de mediação feita pelo professor, entre os saberes de vivências dos estudantes e os saberes científicos, objetos de estudo das aulas. 


\title{
Epistemological reflections on science/chemistry teaching: the potencials of Bachelard scientific pedagogy
}

\begin{abstract}
Nowadays, the technologies has facilitated the reach of information by students, but this information access doesn't mean knowledge access. This situation ends up creating a lack of interest in School Education, which has traditionally been viewed as a way to information and knowledge access. As a result, the school education has the challenge to reinvent itself. In the Science/Chemistry teaching the situation is not different, it's possible to find a disconnected teaching that is also far from being something that makes sense in scientific culture by students. The Bachelard scientific pedagogy and his discussions on the new scientific spirit appears as a questioning practice about the school study objects. Then, the new scientific spirit becomes an effort to epistemological re-orientation in the search for a Science Teaching that has meaning and sense of scientific culture by students, with life-skills training bias.
\end{abstract}

KEYWORDS: Scientific pedagogy. Epistemology. Science teaching. 


\section{NOTAS}

\section{REFERÊNCIAS}

BACHELARD, Gaston. A Epistemologia. O Saber da Filosofia. Edições 70. Rio de Janeiro. 1971.

BACHELARD, Gaston. A formação do espírito científico. Editora Contraponto 2005.

BACHELARD, Gaston. O novo espírito científico. Abril Cultural. Rio de Janeiro. 1979.

FONSECA, Dirce Mendes. A pedagogia científica de Bachelard: uma reflexão a favor da qualidade da prática e da pesquisa docente. Educação e Pesquisa, v. 34, n.2, 361-370, 2008.

GALLIAZI, Maria do Carmo; GONÇALVES, Fábio Peres. A natureza pedagógica da experimentação: uma pesquisa na licenciatura em Química. Química Nova, vol. 27, n. ${ }^{\circ}$ 2, 326-331, 2004.

JAPIASSÚ, Hilton. Para ler Bachelard. Livraria Francisco Alves Editora, 1976.

LOBO, Soraia Freaza. O ensino de química e a formação do educador químico, sob o olhar bachelardiano. Ciência \& Educação, v. 14, n. 1, pg 89-100, 2008.

LOPES, Alice Casimiro. Contribuições de Gaston Bachelard ao Ensino de Ciências. Enseñanza de Las Ciencias, v. 11, n.3, 324-330, 1993.

LOPES, Alice Casimiro. Currículo e epistemologia. ljuí, Editora Unijuí, 2a Ed. 2007.

MALDANER, Otavio Aloisio. Formação inicial e continuada e Professores de Química. ljuí, Editora Unijuí, 1aㅡ. 2003.

PRAIA, João; CACHAPUZ, António; GIL-PÉREZ, Daniel. A Hipótese e a Experiência em Educação em Ciência: Contributos para uma reorientação epistemológica. Ciência \& Educação, v. 8, n.2, 253-262, 2002.

SANGIOGO, F. A; ZANON, L. B. Conhecimento Cotidiano, Científico e Escolar: Página | 352 Especificidades e Inter-Relações enquanto Produção de Currículo e de Cultura. Cadernos de Educação.144-164 janeiro/abril, 2014. 
SILVA, D.P. (Org.) Oficinas temáticas no ensino público: formação continuada de professores. Secretaria da Educação, Coordenadoria de Estudos e Normas Pedagógicas. São Paulo: FDE,2007.108 p.

WEBER, Max. A Ciência como Vocação. Ciência e Política: duas vocações. São Paulo: Cultrix, p.17-52. 2005.

Recebido: 26 fev. 2015

Aprovado: 14 abr. 2016

DOI: 10.3895/rbect.v9n1.2800

Como citar:

RONCH, S. F. A.; DANYLUK, O. S.; ZOCH, A. N. Reflexões epistemológicas no ensino de ciências/química: as potencialidades da pedagogia científica de Bachelard. Revista Brasileira de Ensino de Ciência e Tecnologia, v. 9, n. 1, p. 342-353, jan./abr. 2016. Disponível em:

<https://periodicos.utfpr.edu.br/rbect/article/view/2800>. Acesso em: xxx. Correspondência:

Sthefen Fernando Andrade Da Ronch

BR 285, 99052-900, Passo Fundo, Rio Grande do Sul

Ocsana Sonia Danyluk

BR 285, 99052-900, Passo Fundo, Rio Grande do Sul Alana Neto Zoch

BR 285, 99052-900, Passo Fundo, Rio Grande do Sul

Direito autoral: Este artigo está licenciado sob os termos da Licença Creative Commons-Atribuição 4.0 Internacional. 